\title{
Determination of microbial growth and survival in salad vegetables through in vitro challenge test
}

\author{
Farahnaaz Feroz, Jessica Das Senjuti, Rashed Noor* \\ Dept. of Microbiology, Stamford University Bangladesh, Dhaka, Bangladesh \\ Email address: \\ farahnaazf88@yahoo.com (F. Feroz), jessicadas.stamford@gmail.com (J. D. Senjuti),noor.rashed@yahoo.com (R. Noor)
}

\section{To cite this article:}

Farahnaaz Feroz, Jessica Das Senjuti, Rashed Noor. Determination of Microbial Growth and Survival in Salad Vegetables through in Vitro Challenge Test. International Journal of Nutrition and Food Sciences. Vol. 2, No. 6, 2013, pp. 312-319.

doi: $10.11648 / j . j$ infs.20130206.18

\begin{abstract}
Current study attempted to examine the growth and subsequent survival of the common spoilage bacteria in vegetable samples collected from Dhaka, Bangladesh. Carrot, cucumber, tomato and lettuce samples were obtained from local markets and rendered free of contaminants. Each sample was then inoculated separately with an array of 9 test bacteria, resulting in the initial load of $10^{5} \mathrm{cfu} / \mathrm{g}$. The results revealed more than 6-log reduction of Salmonella spp. in carrot and tomato samples, Shigella spp. in carrot, lettuce and cucumber samples, Aeromonas spp. in tomato samples, Pseudomonas spp. in lettuce samples, and Listeria spp. in cucumber samples. No significant reduction in $E$. coli was observed in the cucumber samples, while in carrots and tomato samples, approximately $2-\log$ reductions was found. Demonstration of the capacity of vegetables to influence microbial growth would further aid in the maintenance of the food quality and stability as well as their shelf life. Conducting such experiments after the quantification of spoiling microorganisms thus imparts a complete bacteriological profile, which is of public health significance.
\end{abstract}

Keywords: Vegetables, Microorganisms, Growth, Challenge Test, Consumer Safety

\section{Introduction}

The practice of consuming fresh vegetables remains popular around the world due to their nutritional value and the ease of availability [31, 34, 35]. However, fresh vegetables may come in contact with an array of microorganisms resulting in various diseases $[5,7,17,22$, 27, 30, 33]. Contamination and growth of spoilage microorganisms usually limit the shelf life of vegetables [19, 28]. Growth of microorganisms in vegetables depends on various intrinsic and extrinsic factors, including acidity, water activity, redox potential, etc. $[6,14]$.

In order to observe the growth pattern of microorganisms in food grade chemicals or pharmaceutical products, during the designated shelf life, laboratories often perform Microbiological Challenge Test (MCT), which involves the intentional inoculation of specific microorganisms into a food product followed by incubation of the product under controlled environmental conditions [21]. The concept of challenge test evolved as a biological test of pharmaceutical products [20], while its use in food or food products, to determine food quality, has not been established [25, 26, 29]. Such type of tests are generally undertaken to meet two objectives: firstly, to assess the growth potential of specific organisms and secondly, to estimate the maximum growth rate [2]. The growth potential is defined as difference between $\log _{10} \mathrm{cfu} / \mathrm{g}$ of final and initial concentrations of inoculated microorganisms [2]. Thus, it becomes possible to predict the survival potential of microorganisms towards food products that can be analyzed to establish the product stability. Demonstration of capacity of vegetables in influencing microbial growth would aid in establishing food quality and stability as well as their shelf life. Conducting such experiments after the characterization of spoilage microorganisms thus imparts a complete bacteriological profile, which is of public health significance.

A number of studies have been carried out previously to detect the extent of microbiological contamination in fresh salad vegetables, but studies attempting to describe the survival of microorganisms in vegetables are limited $[1,5$, $10,12,27]$. Identifying the prevalence of microorganisms among the fresh-cut vegetables might aid in determining the ability of such foods to serve as substrates to enhance the growth of the spoilage microflora. Execution of in vitro 
challenge test of these vegetables is further expected to generate important data regarding food hygiene and safety. It would reveal sanitary conditions of raw vegetables and provide important information regarding the type and nature of pathogens present in vegetables and their survival mechanism in fresh produce.

Basing on these premises, the present study attempted to examine the growth and survival potential of spoiling microflora and pathogens including; E. coli, Staphylococcus spp., Vibrio spp. and Klebsiella spp., Salmonella spp., Shigella spp., Pseudomonas spp., Aeromonas spp. and Listeria spp. among the commonly consumed raw vegetables including cucumber (Cucumis sativus), lettuce (Lactuca sativa), tomatoes (Solanum lycopersicum) and carrots (Daucus carota) in Dhaka, Bangladesh.

\section{Methods}

\subsection{Study Area, Sampling, and Sample Processing}

Vegetable samples of 4 categories (tomato, lettuce; cucumber and carrot) were collected randomly from local groceries, within a time frame of July 2012 - December 2012 Samples were collected early in the morning and transported to the laboratory as soon as possible, according to the method suggested by American Public Health Association [4].

\subsection{Microbiological Analysis and Biochemical Tests}

Prior to the challenge test, the initial identification and enumeration of pathogenic bacteria and fungi in the raw vegetable samples was done as described in previous studies [27]. Twenty five grams (25g) of each sample was homogenized with $225 \mathrm{ml}$ buffer peptone water and serial dilutions were prepared up to $10^{-6}$ following the standard methods for plating [8]. A volume of $0.1 \mathrm{ml}$ from each sample suspension was spread onto nutrient agar (NA, Himedia, India) and incubated at $37{ }^{\circ} \mathrm{C}$ for 24 hours for enumerating total viable bacteria (TVB). Sabouraud Dextrose Agar (SDA, Himedia, India) was inoculated followed by incubation at $25^{\circ} \mathrm{C}$ for 48 hours for the isolation of fungi. For enumerating the total fecal coliform (TFC), 0.1 $\mathrm{ml}$ of each sample was spread onto membrane fecal coliform (mFC) agar (Himedia, India), and incubated at $44.5{ }^{\circ} \mathrm{C}$ for 24 hours. For the isolation of Escherichia coli and Klebsiella spp., $0.1 \mathrm{ml}$ of suspension was spread over MacConkey agar for each samples and incubated at $37{ }^{\circ} \mathrm{C}$ for $18-24$ hours. 0.1 $\mathrm{ml}$ of suspension was spread onto mannitol salt agar (MSA, Himedia, India) for the estimation of Staphylococcus aureus and the plates were incubated at $37^{\circ} \mathrm{C}$ for 24 hours. For the enumeration of Listeria spp., $0.1 \mathrm{ml}$ of suspension was spread onto Listeria identification media and plates were incubated at $37{ }^{\circ} \mathrm{C}$ for 24 hours.

Enrichment [9] was performed for Salmonella and Shigella spp. in the selenite cystine broth (SCB). One ml of homogenized sample suspension was transferred to SCB followed by incubation at $37{ }^{\circ} \mathrm{C}$ for 6 hours, and serial dilutions were made up to $10^{-6}$, from which $0.1 \mathrm{ml}$ was spread onto Salmonella-Shigella (SS) agar (Himedia, India) followed by incubation at $37{ }^{\circ} \mathrm{C}$ for 24 hours. For the enrichment of Vibrio spp., $1 \mathrm{ml}$ of homogenized sample suspension was transferred to alkaline peptone water (APW) and incubated at $37{ }^{\circ} \mathrm{C}$ for 6 hours. $0.1 \mathrm{ml}$ of suspension from $10^{-6}$ dilution was spread onto TCBS agar (Himedia, India), followed by incubation al $37^{\circ} \mathrm{C}$ for 24 hours. Finally, the standard biochemical tests were performed to confirm the identity of all the isolates found within the vegetable samples by the previously described methods $[3,8]$.

\subsection{Processing of Vegetable Samples to be Challenged}

Prior to introducing the test bacteria into the vegetables, all 4 samples were washed with distilled water and with $90 \%$ alcohol to eliminate the microbial flora from the vegetable surface. 10 grams of each sample were homogenized with 90 $\mathrm{ml}$ buffered peptone water (BPW). All samples, including controls, were centrifuged for 5 minutes at $5000 \mathrm{rpm}$, supernatants were removed and BPW was again added to make a volume of $10 \mathrm{ml}$, followed by another round of centrifugation. Washing with BPW was carried out three times in total and the resulting pellets were treated twice with $90 \%$ alcohol followed by the final treatment with $70 \%$ alcohol, following the same technique used for washing with BPW. One hundred (100) $\mu$ l of each sample was plated on to Nutrient agar media and the complete abolition of intrinsic contaminating microorganisms [27] was monitored through the loss of the colony forming units (CFUs) on the plates. Samples were stored in $-4{ }^{\circ} \mathrm{C}$ until use.

\subsection{Preparation of Strains Used for Challenge Test}

Bacterial test strains were obtained from the previously preserved stock cultures of $\mathrm{T}_{1} \mathrm{~N}_{1}$ media; isolated from the different vegetable samples by our laboratory [27]. The bacterial strains were sub-cultured on the nutrient agar medium by means of streak-plate-technique [8] and maintained until full visible colonies were achieved. The actively growing bacterial colonies on the agar plates were found after the incubation period of 24 hours at $37{ }^{\circ} \mathrm{C}$. One loop full of the each pure culture of E. coli, Klebsiella spp., Vibrio spp., Staphylococcus spp., Listeria, Salmonella, Shigella, Aeromonas and Pseudomonas were transferred into $9 \mathrm{ml}$ sterile normal saline tubes. After a 6 hour incubation period at $37{ }^{\circ} \mathrm{C}$ [15], the cell density of approximately $1.5 \times 10^{5} \mathrm{cfu} / \mathrm{g}$ (compared with McFarland Standard OD 0.5) was observed in each test bacterial suspension.

\subsection{Inoculation Strategy and Assessment of Growth}

In order to execute challenge with specific bacterial species, each vegetable suspension $(10 \mathrm{ml})$, excluding the controls, were inoculated with $100 \mu$ l of bacterial suspension resulting in the initial load of $\sim 10^{5} \mathrm{cfu} / \mathrm{g}$. The inoculated samples underwent incubation at $37{ }^{\circ} \mathrm{C}$ for 14 days, with enumeration of bacterial load at every 24-hour intervals, 
using standard spread plate technique $[8,15]$. As the current study was conducted in vitro, incubation conditions were set for optimal growth to efficiently examine vegetables as a microbial growth supporting media. Un-inoculated sterile vegetable samples were also incubated in similar conditions (control) with enumeration of bacterial load at every 24-hour intervals. Serial dilutions of all samples were prepared up to $10^{-6}$ and plated onto Luria Bertani (LB, Himedia, India) agar. The experiments were performed independently three times.

\subsection{Assessment of Reduction in Bacterial Load}

In order to assess the growth potential of artificially inoculated bacterial species in the samples studied, the log reduction and percent reduction were calculated [2]. As the initial load at 0 hour of inoculation was $\sim 10^{5} \mathrm{cfu} / \mathrm{g}$ (artificially introduced into the media), which could be lesser than the final growth after 2 weeks, the maximal load (cfu/g) after 24-48 hours was considered instead of that initial load (cfu/g) in order to assess the growth decay. Thus deducing the final load $(\mathrm{cfu} / \mathrm{g}$ ) from the maximum growth (cfu/g) point would infer the accurate reduction of microorganisms inoculated in the samples, which in turn might reveal the bacterial survival potential as well as the product stability in microbiological aspect.

\section{Results}

\subsection{Bacterial Load in Salad Vegetables}

Prior to challenging the vegetables with specific bacterial isolates, all the samples were first assessed microbiologically. Results were in cohort with previous studies conducted in our laboratory, reveling huge numbers of fecal coliforms, Escherichia coli, Staphylococcus aureus and Listeria spp. were detected [27]. Next we attempted to determine the fate of bacteria once introduced into the commonly consumed vegetables.

\subsection{Survival of Bacteria in the Vegetable Samples Studied}

Our results portrayed the growth pattern of different bacterial species in the salad vegetable samples up to 14 days. The initial loads of the pathogens in the vegetable samples, measured after inoculation, ranged from $10^{3}-10^{5}$ $\mathrm{cfu} / \mathrm{g}$. The bacterial loads increased significantly in the first few days of the challenge test before any substantial decrease in growth was observed. Carrot (Fig. 1) presented the highest reduction ( $>8 \log$ ) of growth for Shigella spp., followed by around 5-log reduction in Salmonella spp. Aeromonas spp., Listeria spp., Klebsiella spp., Vibrio spp. and $E$. coli exhibited 1 to $2 \log$ reduction after 14 days, whereas staphylococci and Pseudomonas spp. exhibited the highest survival rates in cucumber samples, presenting itself with the least reduction frequencies ( $>90 \%$ survivors).
A

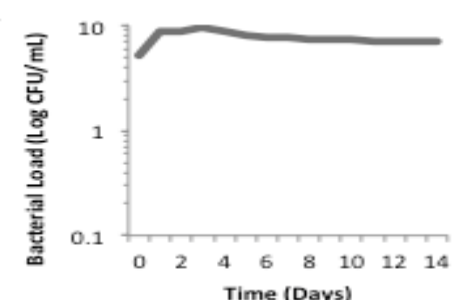

$\mathrm{D}$
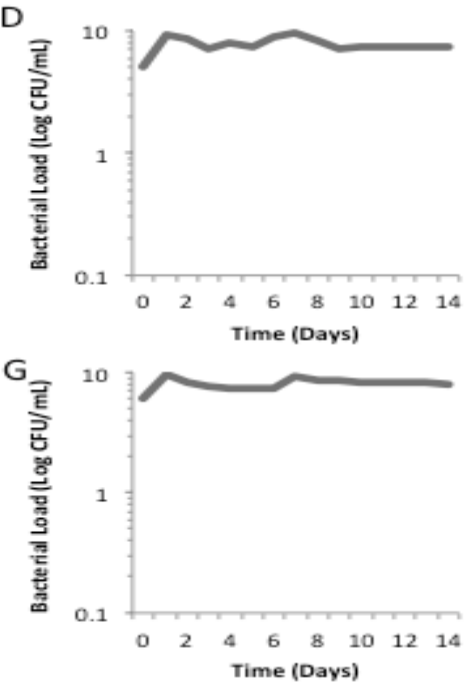

B

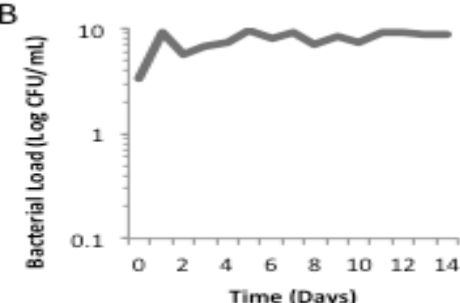

$\mathrm{E}$
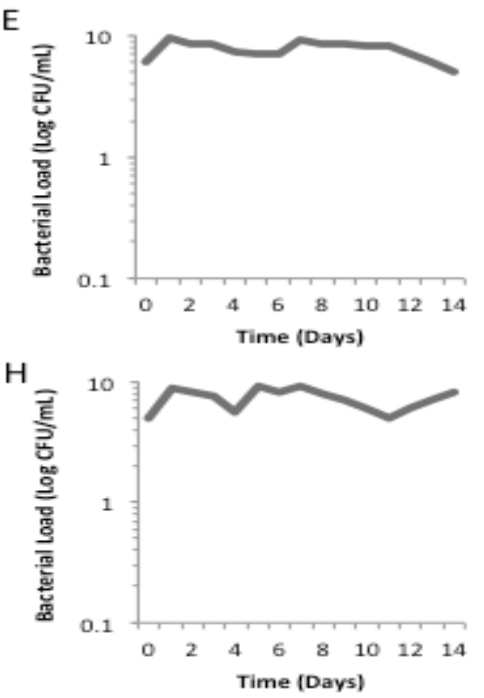
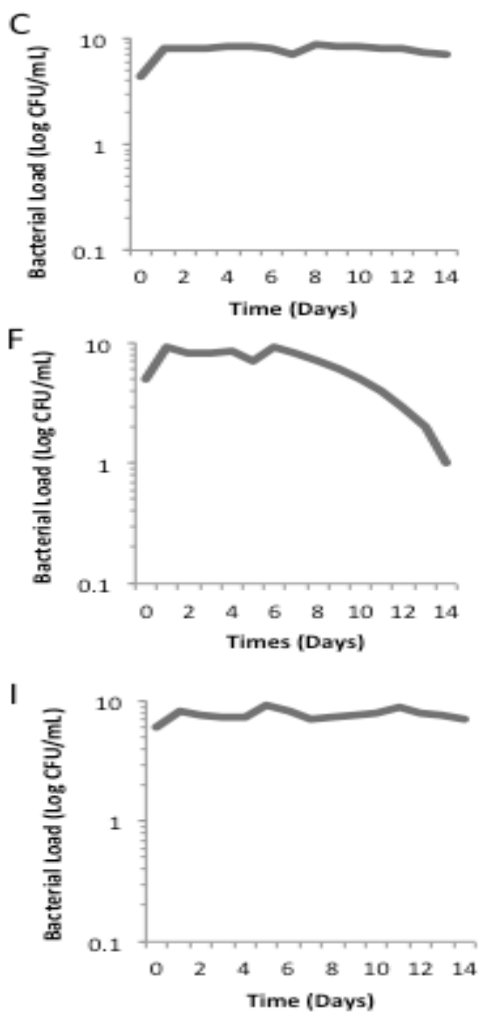

Figure 1. Growth patterns of bacterial species (A. E. coli, B. Staphylococcus spp., C. Vibrio spp., D. Klebsiella spp., E. Salmonella spp., F. Shigella spp., G. Aeromonas spp., H. Psuedomonas spp., I. Listeria spp.) used to challenge carrot samples. The optical density $\left(O D_{600}\right)$ of different bacterial culture were adjusted with that of the McFarland standard $\left(O D_{600} 0.5\right)$ and then introduced into the vegetable samples. Bacterial enumeration was performed on every 24 hour up to 14 days. 

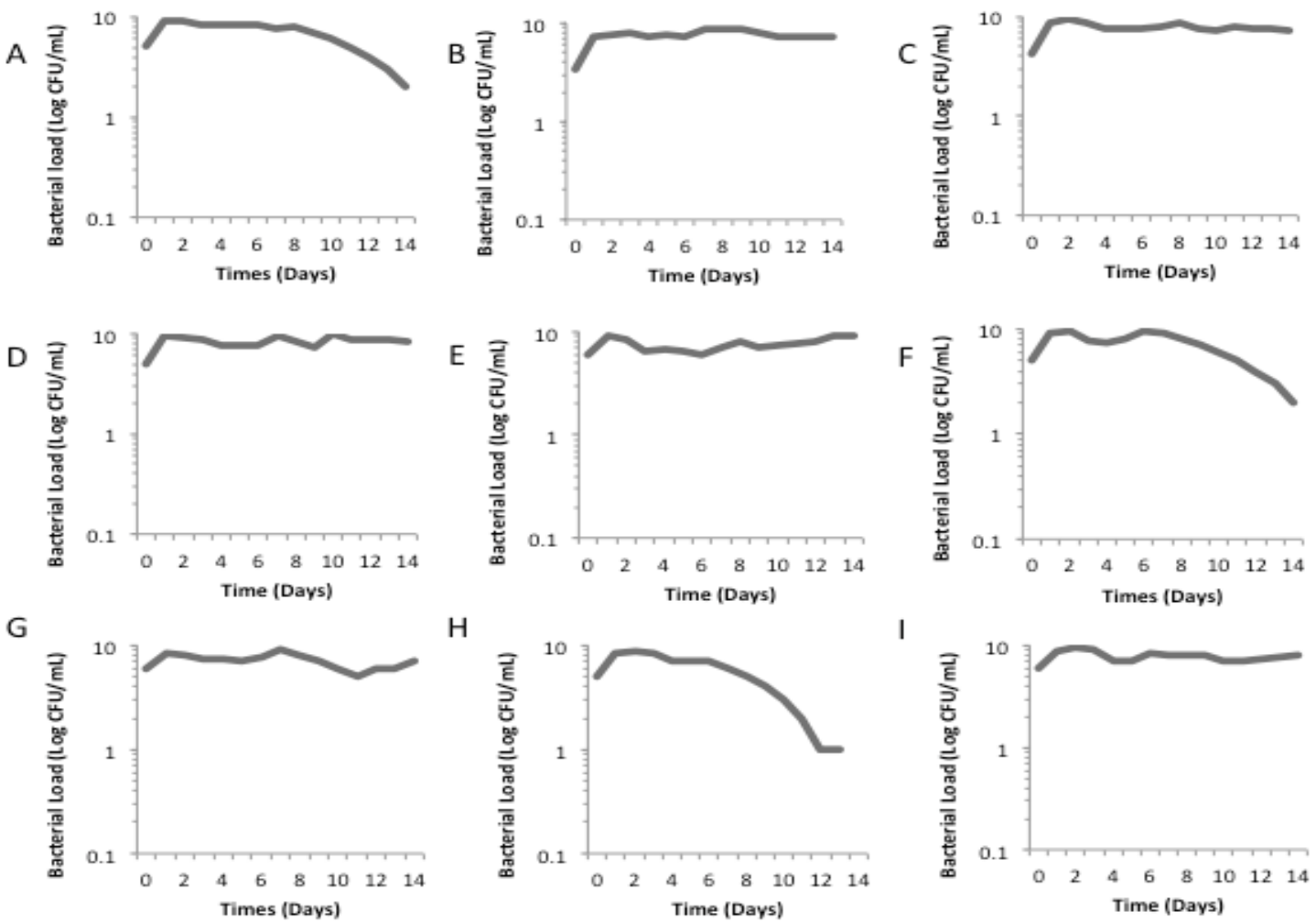

Figure 2. Growth patterns of bacterial species (A. E. coli, B. Staphylococcus spp., C. Vibrio spp., D. Klebsiella spp., E. Salmonella spp., F. Shigella spp., G. Aeromonas spp., H. Psuedomonas spp., I. Listeria spp.) used to challenge lettuce samples. The optical density $\left(O D_{600}\right)$ of different bacterial culture were adjusted with that of the McFarland standard $\left(O D_{600} 0.5\right)$ and then introduced into the vegetable samples. Bacterial enumeration was performed on every 24 hour up to 14 days.
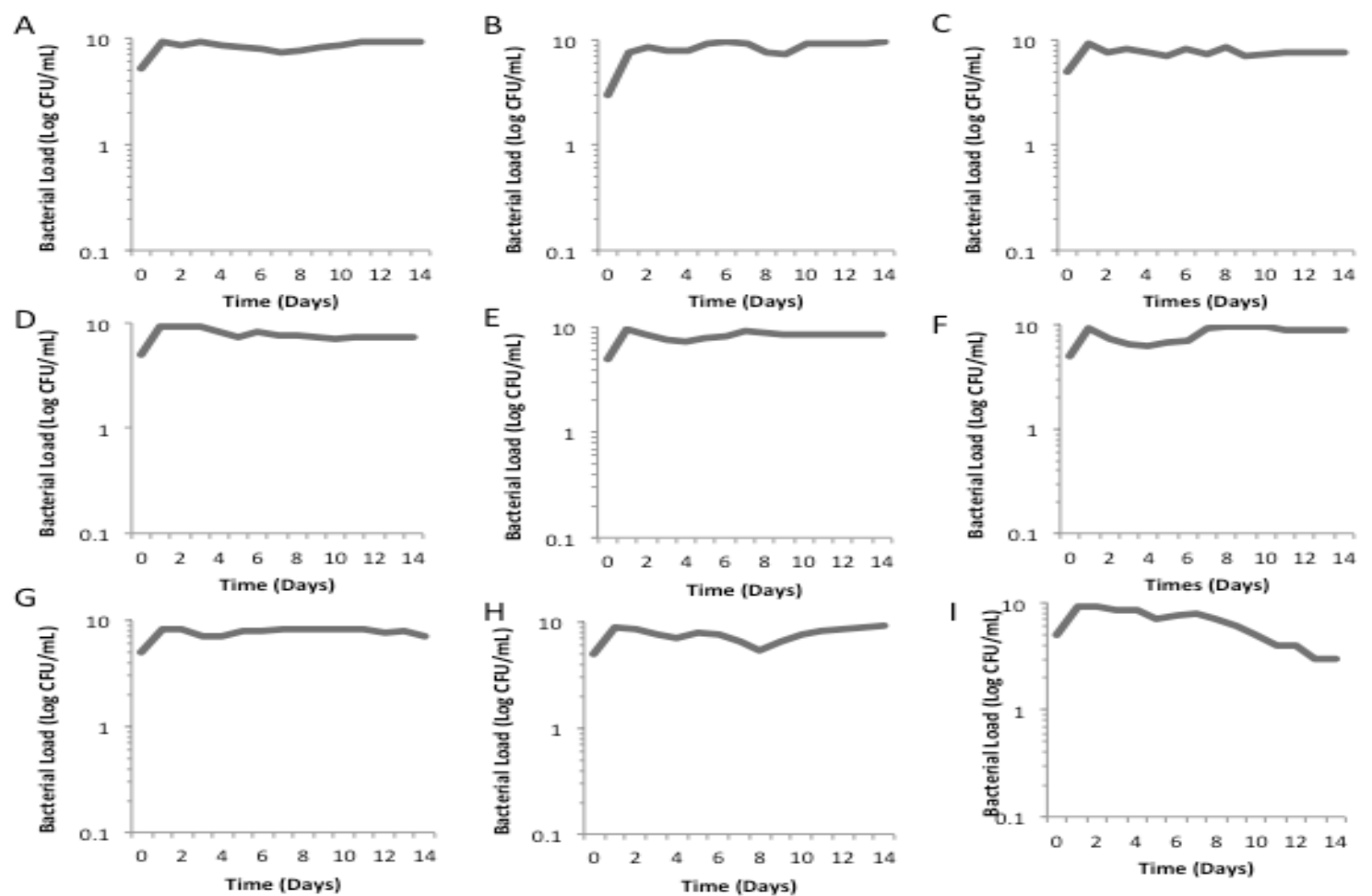

Figure 3. Growth patterns of bacterial species (A. E. coli, B. Staphylococcus spp., C. Vibrio spp., D. Klebsiella spp., E. Salmonella spp., F. Shigella spp., G. Aeromonas spp., H. Psuedomonas spp., I. Listeria spp.) used to challenge cucumber samples. The optical density $\left(O D_{600}\right)$ of different bacterial culture were adjusted with that of the McFarland standard $\left(O D_{600} 0.5\right)$ and then introduced into the vegetable samples. Bacterial enumeration was performed on every 24 hour up to 14 days. 

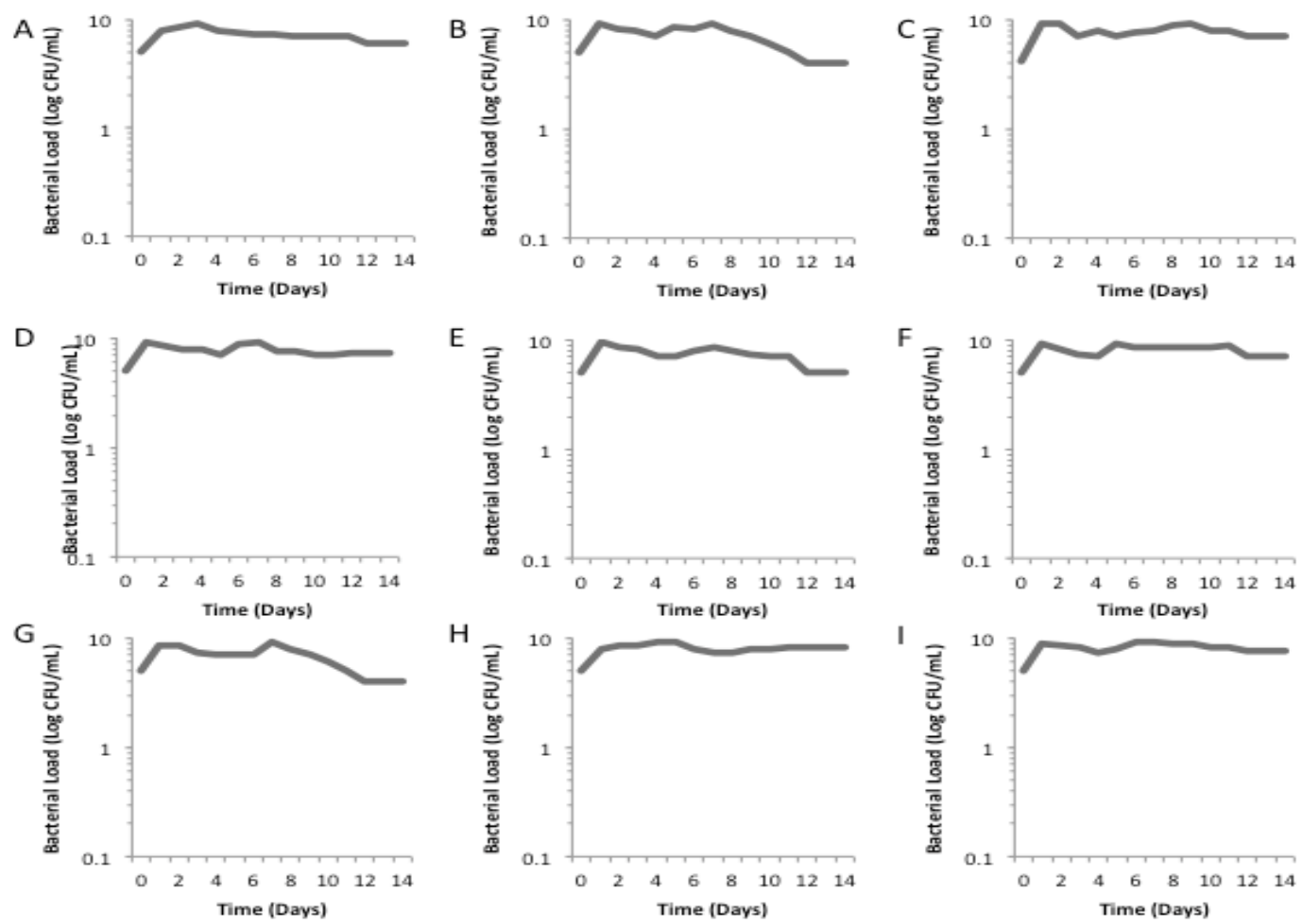

Figure 4. Growth patterns of bacterial species (A. E. coli, B. Staphylococcus spp., C. Vibrio spp., D. Klebsiella spp., E. Salmonella spp., F. Shigella spp., G. Aeromonas spp., H. Psuedomonas spp., I. Listeria spp.) used to challenge tomato samples. The optical density (OD) of different bacterial culture were adjusted with that of the McFarland standard (OD 0.5) and then introduced into the vegetable samples. Bacterial enumeration was performed on every 24 hour up to 14 days.

Lettuce (Fig. 2) samples expressed complete inhibition of Pseudomonas growth within 14 days, while a significant reduction of more than 7- log was observed in samples inoculated with Shigella spp. and E. coli. Aeromonas spp., Listeria spp., Klebsiella spp., and Vibrio spp. exhibited around 1 to 2-log reduction. Interestingly, Staphylococcus spp. and Salmonella spp. were found to survive in lettuce.

In cucumber samples (Fig. 3), growth of Listeria spp. was suppressed by more than 6 -log, followed by around 1 to 2-log reduction in Salmonella spp., Aeromonas spp., Staphylococcus spp., Klebsiella spp., and Vibrio spp. after 14 days. On the contrary, Shigella spp., Pseudomonas spp. and E. coli showed the lowest survival rates in carrot samples. In tomato (Fig. 4), Pseudomonas spp. survived completely, without showing any reduction, while Listeria spp., Klebsiella spp., Shigella spp., E. coli, Salmonella spp. and Vibrio spp. exhibited a decline in growth by approximately 2-log reduction. Aeromonas spp. and Staphylococcus spp. expressed significant reductions in growth frequencies (around $5 \log$ reduction); however, the surviving populations were estimated to be more than $40 \%$.

\section{Discussion}

Information on the survival potential of vegetable spoiling bacteria is limited and such knowledge could be of significance in determining vegetable storage period and shelf life, and may contribute further to food safety and quality [2]. Present study thus focused on the ability of the salad vegetables to either support or suppresses the growth of vegetable spoiling microorganisms. Our study employed a simulation strategy involving the microbiological challenge tests in vitro for the first time in vegetable research, in Bangladesh. Challenge tests, as stated earlier, are more commonly performed on pharmaceutical products [20]. It would, however, be beneficial to determine the ability of these products to maintain the growth of spoilage and pathogenic organism, through microbiological challenge tests, in order to lower to risk of food poisoning [25]. Therefore, noting the suggestive importance to examine the quality of products and its ability to maintain microorganisms, we estimated the tenure of the viable and culturable microorganisms in the vegetable samples. Thus our investigation attempted to ease the burden of food borne illnesses on an individual's health and the health care system.

In our study, tomato samples were found to facilitate the growth of almost all the test bacteria, carrot samples were also found to favor the growth of all bacteria employed except Shigella spp., cucumber samples were observed to facilitate the growth of bacteria except Pseudomonas and to some extent, Listeria spp., and the lettuce samples were found to inhibit the growth of Shigella spp., Pseudomonas spp. and E. coli (Table 1). Notably, growth of Pseudomonas spp. remained unaffected in carrot, tomato and cucumber samples, Salmonella spp. in lettuce and cucumber samples, and Listeria spp. in all samples except for cucumbers. E. coli was found to be potential survivor in fresh vegetables while the load of Listeria spp. reduced at a relatively faster rate. 
Interestingly, cucumber, followed by lettuce, was found to favor the microbial growth for a longer period of time compared to the other vegetable samples.

Table 1. Survival of test bacteria in the specified salad vegetable samples

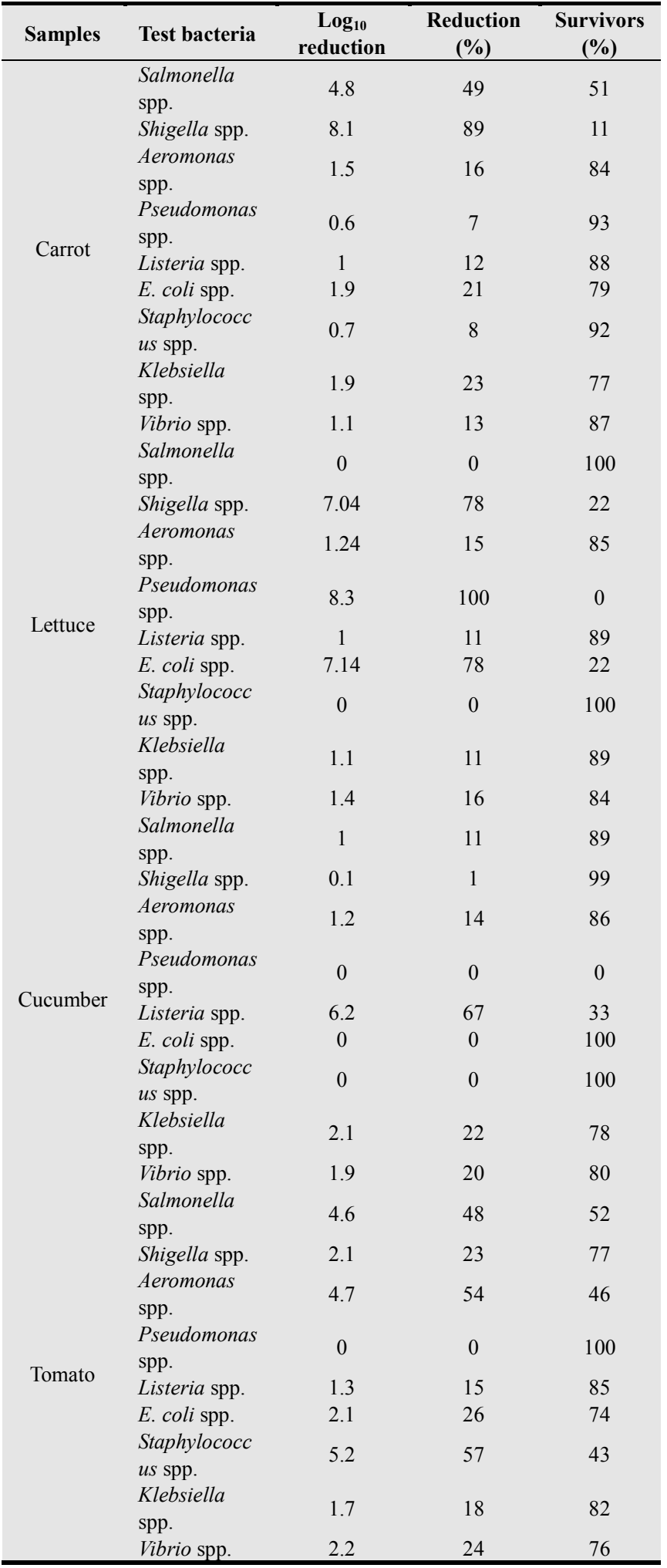

In some of the tested samples, after a period of gradually declining growth, there was a sudden increase in growth before returning to a declining trend. One possible reason could be the "phoenix phenomenon" which indicates that the samples were tested beyond its shelf life, or stored in conditions that promoted spoilage, which led to a period in which microorganism cells recovered resulting in increased growth in product [13]. In this case, the relapse in growth may have been caused by the conditions used for the in vitro study. Of the pathogens studied, Staphylococcus spp. and E. coli showed lowest reduction in growth, establishing themselves as the pathogens with the highest survival potential. This could be an alarming fact, due to both pathogens serving as normal flora of the body and the former being present on most surfaces. It could also indicate high levels of support for the growth of organisms, which can easily be transmitted through skin contact and fecal contamination. Frequent exposure to enteric diseases upon consumption of raw vegetables might be thus explained through the survival of these bacteria $[11,32]$.

The decrease in bacterial growth might be due to the normal growth inhibitory strategy resulting from the turning down of several sets of genes in the stationary phase $[18,24]$ or due to the limiting substrates. Conversely, as observed, in certain cases, an increase in bacterial burden after the reduction was not unexpected due to the expression of certain stress responsive genes [23]. Nevertheless, the final reduction in bacterial burden in maximum cases was assumptive of the gradual utilization of substrates to the limiting concentrations by the bacterial population. Several intrinsic factors as stated earlier might also account for such variations in the growth patterns $[6,16]$.

Finally, demonstrating the capacity of vegetables to influence microbial growth would largely contribute to sustaining food quality and stability as well as establishing shelf life. Current experiments figured out not only the fresh vegetable spoilage microorganisms but also elaborately delineated their survival potential, thus imparting a complete bacteriological profile, which is of public health significance. Such strategy is replicable in resource poor settings devoid of the molecular studies on microbial growth influencing factors. Execution of this method may contribute to determining microbiological quality control of food products.

\section{Conclusion}

Several studies have been carried out previously to detect the extent microbiological contamination in fresh salad vegetables; however, the knowledge on the survival of the contaminant is still obscure. Current study employed the microbiological challenge tests for the first time in vegetable research in Bangladesh. Presented results sufficiently projected the survival potential of microorganisms in commonly consumed vegetables. It would be thus advantageous to resolve the ability of foods to serve as microbiological media, in order to lower the risk of food poisoning, and hence further contributing to the existing knowledge on food borne microorganisms. 


\section{Acknowledgements}

We thank Stamford University Bangladesh for providing laboratory facilities and financing the research.

\section{References}

[1] Abadias, M., Usall, J., Anguera, M., Solsona, C. and Viñas I. "Microbiological quality of fresh, minimally processed fruit and vegetables, and sprouts from retail establishments", International Journal of Food Microbiology, vol. 123, No. 1-2, pp. $121-129,2008$

[2] AFSSA (Agence Franc,aise de Se'curite' Sanitaire des Aliments) (2008), "Technical guidance document on shelf-life studies for Listeria monocytogenes in ready-to-eat foods", Available at: http://ec.europa.eu/food/food/biosafety/salmonella/docs/shel flife listeria_monocytogenes en.pdf (Accessed 18 April 2013).

[3] Alfrad, E.B, Bensons Microbiological Applications, Mcgraw-Hill: New York, 2007.

[4] APHA (American Public Health Association), Standard Methods for the Examination of Water and Wastewater, American Public Health Association: Washington, D.C., 1998.

[5] Beuchat, L.R., "Pathogenic microorganisms associated with fresh produce", J. Food Prot., Vol. 59, No. 2, pp. 204-216, 1996.

[6] Bibek R., Fundamental of Food Microbiology, CRC press, Boca Raton: London New York Washington D.C., 2005.

[7] Burnett, S.L. and Beuchat, L.R., "Human pathogens associated with raw produce and unpasteurized juices, and difficulties in contamination", J. Indust. Microbiol. Biotechnol., Vol. 27, No. 2, pp. 104-110, 2001.

[8] Cappuccino, J.G. and Sherman, N., Microbiology- A Laboratory Manual, The Benjamin/Cummings Publishing Co. Inc.: California, 1996

[9] Colwell, R.R., "Bacterial death revisited", in Colwell, R. R. and Grimes D. J. (Eds), Non-culturable microorganisms in the environment, American Society of Microbiology: Washington DC, USA, pp. 325-342, 2001.

[10] Cordano, A.M. and Jacquet, C., "Listeria monocytogenes isolated from vegetable salads sold at supermarkets in Santiago, Chile: Prevalence and strain characterization", International Journal of Food Microbiology, Vol. 132, No. 2-3, pp. 176-179, 2009.

[11] Cray, W.C.J. and Moon, W.H., "Experimental infection of calves and adult cattle with Escherichia coli O157:H7." Appl. Environ. Microbiol., Vol. 61, No. 4, pp. 1586-1590, 1995.

[12] Fain, A.R., "A review of the microbiological safety of fresh salads", Dairy, Food, and Environmental Sanitation, Vol. 16, No. 3, pp. 146-149, 1996.

[13] FDA (U.S. Food and Drug Administration) (2009), "Elimination of Microbial Hazards on Fresh and Fresh-Cut

[14] Produce", Chapter IV, Outbreaks Associated with Fresh and Fresh-Cut Produce. Incidence, Growth, and Survival of
Pathogens in Fresh and Fresh-Cut Produce.

[15] FDA (U.S. Food and Drug Administration) (2001a), "Evaluation and Definition of Potentially Hazardous Foods", Chapter 3, Factors that Influence Microbial Growth, available http://www.fda.gov/Food/FoodScienceResearch/SafePractic esforFoodProcesses/ucm094145.htm (Accessed 25 April 2013)

[16] FDA (U.S. Food and Drug Administration) (2001b), "Evaluation and Definition of Potentially Hazardous Foods", Chapter 6, Microbiological Challenge Testing. Available at: http://www.fda.gov/Food/FoodScienceResearch/SafePractic esforFoodProcesses/ucm094154.htm (Accessed 25 April 2013).

[17] Gould, G.W., "Preservation: past, present and future", Br. Med. Bull., Vol, 56, No. 1, pp. 84-96, 2004.

[18] Guo, X., van Iersel, M.W., Chen, J., Brackett, R.E., and Beuchat, L. R. , "Evidence of association of salmonellae with tomato plants grown hydroponically in inoculated nutrient solution”, Appl. Environ. Microbiol., Vol. 68, No. 7, pp. 3639-3643, 2002.

[19] Kabir, M.S., Yamashita, D., Noor, R. and Yamada, M., "Effect of $\sigma^{\mathrm{S}}$ on $\sigma^{\mathrm{E}}$-directed cell lysis in Escherichia coli early stationary phase", J. Mol. Microbiol. Biotechnol., Vol. 8, No. 3, pp. 189-194, 2004.

[20] King, A.D. and Bolin, H.R., "Physiological and microbiological storage stability of minimally processed fruits and vegetables", Food Technol., Vol. 43, No. 2, pp. $132-135,1989$.

[21] Manou, I., Bouillard, L., Devleeschouwer, M.J. and Barel, A.O., "Evaluation of the preservative properties of Thymus vulgaris essential oil in topically applies formulations under a challenge test", Journal of Applied Microbiology, Vol. 84, No. 3, pp 368-367, 1988.

[22] NACMCF (National Advisory Committee on Microbiological Criteria for Foods), "Parameters for Determining Inoculated Pack/Challenge Study Protocols", Journal of Food Protection, Vol. 73, No. 1, pp. 140-202, 2010.

[23] Nipa, M.N., Mazumdar, R.M., Hasan, M.M., Fakruddin, M., Islam, S., Bhuiyan, H.R. and Iqbal, A., "Prevalence of Multi Drug Resistant Bacteria on Raw Salad Vegetables Sold in Major Markets of Chittagong City, Bangladesh", Middle East Journal of Scientific Research, Vol. 10, No. 1, pp. 70-11, 2011.

[24] Noor, R., Murata, M. and Yamada, M., "Oxidative Stress as a Trigger for Growth Phase-Specific $\sigma^{\mathrm{E}}$ - Dependent Cell Lysis in Escherichia coli", J. Mol. Microbiol. Biotechnol, Vol. 17, pp. 177-187, 2009b.

[25] Noor, R., Murata, M., Nagamitsu, H., Klein, G., Raina, S. and Yamada, M., "Dissection of $\sigma^{\mathrm{E}}$-dependent cell lysis in Escherichia coli: roles of RpoE regulators RseA, RseB and periplasmic folding catalyst PpiD", Genes to Cells, Vol. 14, pp. 885-899, 2009a.

[26] Notermans, S. and Veld, P., "Microbiological challenge testing for ensuring safety of food products", International Journal of Food Microbiology, Vol. 24, No. 1-2, pp. 33-39, 1994. 
[27] Notermans, S., Veld, P., Wijtzes, T. and Mead G.C., "A user's guide to microbiological challenge testing for ensuring the safety and stability of food products", Food Microbiol, Vol. 10, No. 2, pp. 145-57, 1993.

[28] Rahman, F. and Noor, R., "Prevalence of pathogenic bacteria in common salad vegetables of Dhaka metropolis", Bangladesh Journal of Botany, Vol. 41, No. 2, pp. 159-162, 2012.

[29] Robbs, P.G., Bartz, J.A., McFie G. and Hodge N. C., "Causes of decay of fresh-cut celery", Journal of Food Science, Vol. 61, No. 2, pp. 444-448, 1996.

[30] Scott, V.N., Swanson, K.M. J., Freier, T.A., Pruett, W.P., Sveum, W.H., Hall, P.A., Smoot, L. A. and. Brown D. G., "Guidelines for conducting Listeria monocytogenes challenge testing of foods", Food Prot. Trends Vol. 25, No. 11, pp. 818-825, 2005.

[31] Solomon, E.B., Yaron, S. and Matthews, K.R., "Transmission of Escherichia coli O157:H7 from contaminated manure and irrigation water to lettuce plant tissue and its subsequent internalization", Applied Environmental Microbiology, Vol.
68, No. 1, pp. 397-400, 2002.

[32] Southon, S., "Increased fruit and vegetable consumption within the EU: potential health benefits", Food Res. Intl., Vol. 33, No. 3-4, pp. 211-217, 2000.

[33] Starutch, D., "Survival of pathogenic microorganisms and parasites in excreta, manure sand sewage sludge", Rev. Sci. Tech. Off. Int. Epiz., Vol. 10, No. 3, pp. 813-846, 1991.

[34] Wachtel, M.R., Whitehand, L.C. and Mandrell, R.E., "Association of Escherichia coli O157:H7 with preharvest leaf lettuce upon exposure to contaminated irrigation water", Journal of Food Protection, Vol. 65, No.1, pp. 18-25, 2002.

[35] Wargovich, M.J., "Anticancer properties of fruits and vegetables", Horticulture Science, Vol. 35, No. 4, pp. $573-575,2000$.

[36] Zepp, G., Kuchler, F. and Lucier, G., "Food safety and fresh fruits and vegetables: is there a difference between imported and domestically produced products?" Vegetables and Specialties, Situation and Outlook Report, Vol. 274, pp. 23-28, 1998. 